\title{
The Role and Influence of Vihiga County Government in the Implementation of the Early Childhood Development and Education (ECDE) Curriculum
}

\author{
Dr.Peter Mamuli Nyongesa \\ Lecturer, Department of Social Sciences, School of Education and Social Sciences, Kaimosi Friends University \\ College,Kenya
}

\begin{abstract}
The involvement of devolved government in the implementation of an ECDE curriculum is critical to the academic future of preschoolers. The ECDE centers require improvement which calls for enhanced support, financial or otherwise, not only from the county government but from other stakeholders as well. In the wake of a new political dispensation that saw most of hitherto centralized functions of the national government being devolved to county governments, the implementation of ECDE curricula across Kenya too became a devolved function. Accordingly, the purpose of this study was to establish the role and influence of Vihiga County government in the implementation of the Early Childhood Development and Education (ECDE) Curriculum. Gross's Theory of Curriculum Implementation guided this study. The study applied a descriptive survey as the central design targeting ECDE teachers, ECDE curriculum implementation stakeholders, Curriculum Staff Officers, and Quality Assurance Officers in Vihiga County. Stratified random sampling was employed to raise a study sample of $20 \%$. The questionnaire was the main instrument for data collection, but an interview schedule was used too. The study established that the devolved government plays a pivotal role in the process of ECDE curriculum implementation. Furthermore, the study found that the County government of Vihiga has registered significant success in as far as the provision of teaching and learning materials goes, but more effort is required to ensure human resource development which is key in the ECDE curriculum implementation process.
\end{abstract}

Keywords: QUASO, ECDE, Curriculum Implementation, CSO, ECDE Curricula.

DOI: $10.7176 / \mathrm{JEP} / 11-28-07$

Publication date:October $31^{\text {st }} 2020$

\section{INTRODUCTION}

The important role played by the devolved systems of government in the implementation of an ECDE curriculum the world over cannot be over emphasized. In retrospect, effective curriculum implantation can be a real conundrum for preschool teachers but one that should be given primacy bearing in mind that the academic achievement of preschoolers anywhere in the world hinges on it. Accordingly, factors which determine the level of participation of either a national or devolved government in the implementation of an ECDE curriculum are further influenced by the type governance framework. Prior to the promulgation of the new constitution in Kenya in 2010, the implementation of ECDE curriculum remained within the purview of the national government (Kiilu (2018). The outcomes of the promulgation of the new constitution in Kenya were immediate because its positive impact was felt across the entire education sector. The ECDE sub sector became one of the most immediate beneficiaries in the new political dispensation as it saw the drastic increase in enrolment rates of preschoolers which was, in hindsight, not backed by a commensurate increase in resources to facilitate the curriculum implementation process. According to empirical data available, participation rate of preschoolers rose more than threefold to attain over $60 \%$ participation which was a major boost in the quest to achieve Education For All. The decentralization of ECDE services which were hitherto a function of the National Government undoubtedly gave a fresh impetus in the increase of ECDE participation rate. And as Lutta (2015) asserts, the devolved government influences the implementation process of an ECDE curriculum through enhancement of ECDE supportive roles. Primarily, devolved government supports the teachers to ensure a smooth transition of the preschoolers to primary education by laying the foundation of a thorough ECDE curriculum. According to Wangila, Omulando, and Too (2017), a strong educational foundation for preschoolers and their subsequent academic achievement later in life reflects the amount of resources the government invested into the ECDE curriculum implementation process. The resources, it must be noted, are not limited to direct funding by the devolved government, but also include the ability of such a government to organize the input or crucial stakeholders in the curriculum implementation process. The stakeholders include, but are not limited to, teachers, Community-Based Organizations, parents, and curriculum implementation support staff. The availability or scarcity of the input of such stakeholders could determine the impact of a devolved government on the implementation on an ECDE curriculum. Lutta (2015) reported that the capacity requirements for the implementation of the ECDE curriculum require an active involvement of the devolved government through the disbursement of requisite resources needed during the implementation process. For example, ECDE centers require both extensive and intensive funding from the 
devolved government to enable timely and successful implementation of an ECDE curriculum.

Wangila, Omulando, and Too (2017), argue that some crucial resources required for the implementation of an ECDE curriculum by a given center might not be under the direct influence of the devolved government, but the county government might influence central stakeholder required in the implementation process. The idea that the devolved government wields immense influence on central stakeholders to the curriculum implementation process is not unique to the Kenyan setting. For instance, Egbo (2013) reported that Nigerian ECDE curriculum implementation process required the devolved government's empowerment of key stakeholders such as Quality Assurance Officers, teachers, parents, and Standards Officers. Nonetheless, the author warns that empowerment of such stakeholders must come second after the government's initial involvement in laying the groundwork for necessary infrastructure required by each stakeholder to play a successful role in the implementation of the ECDE curriculum.

The roles played by each stakeholder are not mutually exclusive. They, for the most part, overlap with the school head being the pivot around which all activities revolve Wakhungu (2019). Consistent with the arguments of Egbo (2013) Wakhungu (2019) also emphasized that the influence and role played by the devolved government in the ECDE curriculum implementation process is the result of government policy.

The successful implementation of an ECDE curriculum through involvement of the devolved government is measured by certain observable indicators. Firstly Ochieng (2018) reported that the direction of ECDE curriculum implementation depends on the devolved government's ability to facilitate training and subsequent placement of ECDE teachers in every center. However, the author emphasize that the highest levels of accountability is required by the devolved government to ensure that every trained ECDE teacher completes a given certificate as stipulated in the ECDE policy guidelines for increased service and content delivery to preschoolers. The devolved government's ease of achieving accountability reflects a milestone in ECDE implementation process because such a feat had not been efficiently implemented by the national government, as reiterated by Smoke (2015). However, it must be noted that devolved governments may fail to reach high accountability levels, thus crippling the ECDE implementation process especially if the resource management strategy is ineffective. And as Obuchere (2011) posits, failure by a devolved government to disburse adequate resources in a timely manner is the main challenge of ECDE curriculum implementation process. For instance the failure to disburse financial resources that are necessary for the procurement of instructional materials may have adverse effect in the ECDE curriculum implementation continuum as suppliers may fail to deliver the said materials owing to nonpayment of previously supplied artifacts. This obviously has a ripple effect as lack of requisite instructional artifacts hinders effective implementation of the curriculum the result of which is poorly prepared preschoolers who are not ready for formal schooling. However, Abdimulingo and Mwirigi (2014) arguments are inconsistent with Obuchere (2011) because they assert that even devolved governments struggle regarding effective management of financial resources during implementation process of ECDE curriculum.

Extensive research has been conducted regarding the status of the ECDE curriculum implementation under the devolved government in Kenya ever since the promulgation of the new constitution. On the contrary, little is known regarding the role and influence of the devolved governments in the implementation of the ECDE curriculum. Accordingly, the purpose of this study was to establish the role and influence of Vihiga County government in the implementation of the ECDE curriculum.

\section{THEORETICAL FRAMEWORK}

The theory of curriculum implementation by Gross et al (1971) guided this study. According to these theorists, the success of curriculum implementation is the result of a combination of many factors which stakeholders have to put in place to the benefit of the learners. Leadership at either school or government level is a necessary input which determines the vigor with which the curriculum implementation process takes place. According to Gross et al. (1971), certain leadership competencies at all school and government levels influences resource usage during the implementation process, the nature and level of management support during curriculum implementation, the nature and number of stakeholders required, the attitudes of the implementation team, and clarity of the implementation objectives guiding the entire implementation process. Furthermore, Gross et al (1971) emphasize that an appropriate policy framework is a necessary ingredient in the curriculum implementation process because it guides necessary reforms required of the existing curriculum for the benefit of the learners. Accordingly, the theory emphasizes role-play by different stakeholders during the curriculum implementation process. Thus, the theory was considered as relevant to the study because it emphasizes the importance of the role played by different stakeholders such as the devolved government in the successful implementation of a curriculum. This implies that the role played by the government cannot be overlooked because every other stakeholder depends on it for empowerment. Therefore, the input of the county government to the successful implementation of an ECDE curriculum cannot be overlooked. The theory emphasizes the need for the awareness of the different roles played by various stakeholders in the curriculum implementation process and the level of involvement of each stakeholder. 


\section{METHODOLOGY}

This section highlights the research methodology that was used to conduct the study with a special focus on the research design, sampling methods adopted and the target population from the study area. Accordingly, the study adopted the descriptive research design in the collection of dat. This followed the suggestions proposed by Creswell (2009), and Bogdan and Biklen (2007) who posit that the research design adopted for a given study should lead to the collection of both intensive and extensive data, and its eventual in-depth examination for making appropriate analyses and conclusions. Additionally Kothlan (2004) asserts that a descriptive research design leads to the collection of data by considering the current conditions of the study area, conditions which have existed recently or existed in the distant past. This method was found appropriate because the population from which the research data was collected was very large and therefore made other methods like direct observation implausible given the time and resource limitations. The target population comprised of Quality Assurance Officers (QUASOs), ECDE teachers, Curriculum Support Staff, and stakeholders, all totaling to 1600 . The collected data was analyzed qualitatively and quantitatively. The qualitative analysis approaches involved the consideration of study objectives to thematically analyze the data, whose presentation involved narrative forms. Quantitative analysis of the data involved descriptive methods of frequencies and percentages.

\section{III.RESULTS AND DISCUSSIONS}

This section covers data analysis, its presentation and interpretation. The purpose of the study was to establish the role and influence of Vihiga County government in the implementation of the Early Childhood Development and Education (ECDE) curriculum. The measure of the achievement of objectives under this study involved consideration of the academic qualifications and experience of the professionals such as the ECDE teachers, the QUASOs, Curriculum Support Staff, and stakeholders (Faith-Based Organizations and Community-Based Organizations). Specifically, this section reflects the policy aspects of the Vihiga County government's involvement in the curriculum implementation process. The policy aspects of curriculum implementation are availability of resources for implementation, and the level of engagement of stakeholders.

\section{A. RESOURCE PROVISION FOR THE IMPLEMENTATION OF THE ECDE CURRICULUM IN} VIHIGA COUNTY

Establishment of the role and influence of devolved government in the implementation of the Early Childhood Development and Education (ECDE) Curriculum in the Context of Vihiga County was the study's central purpose. Thus data was collected to find out the level of Vihiga County government's involvement in as far as resource provision goes in the ECDE curriculum implementation process. The crucial resources analyzed in this case included the human resource, provision of teaching and learning materials, allocation of land necessary for physical activities, and establishment of adequate classrooms to accommodate the ever-increasing number of admissions of preschoolers. Table 1 below shows the results of the data collected from the respondents.

\begin{tabular}{|c|c|c|c|c|c|c|}
\hline \multirow[t]{2}{*}{ Resources } & $\begin{array}{l}\text { Available } \\
\text { Adequate }\end{array}$ & \multirow[t]{2}{*}{ and } & $\begin{array}{l}\text { Available } \\
\text { adequate }\end{array}$ & \multirow[t]{2}{*}{ and not } & \multicolumn{2}{|c|}{$\begin{array}{l}\text { Not } \\
\text { available }\end{array}$} \\
\hline & $\mathrm{F} \%$ & & $\%$ & & & $\%$ \\
\hline ECDE Classrooms & $14 \quad 46.7$ & & 12 & & 2 & 2.3 \\
\hline Human resource (ECDE teachers) & 36.7 & & 36.7 & & 8 & 26.7 \\
\hline ECDE center Playgrounds & 53.3 & & 30 & & 5 & 16.7 \\
\hline $\begin{array}{l}\text { ECDE Teaching and learning } \\
\text { materials }\end{array}$ & 56.7 & & 26.7 & & 5 & 16.7 \\
\hline
\end{tabular}

Table 1 illustrates that close to half $(\mathrm{n}=14,46.7 \%)$ of the respondents agree that Vihiga County government plays a significant role in the construction of ECDE classrooms required during implementation of an ECDE curriculum. Additionally, a further $40 \%(\mathrm{n}=12)$ of the respondents agree that ECDE classroom availability is facilitated by the County government, but the classrooms are not adequate for the implementation of the ECDE curriculum. This leaves under $2 \%$ of the respondents representing those who do not agree that Vihiga County government is directly involved in the provision of the four resource categories investigated in the study. Importantly, Table 1 illustrates a notable pattern across the four resource categories. Firstly, agreement that the county government supplies adequate resources (ECDE teaching and learning materials, Classrooms, playgrounds, and Human resources) has the highest rating. For instance, one of the interviewees observed:

"I have served in my capacity for many years under the national government, but I was always constrained by resources required to implement the ECDE curriculum. Everything changed under the devolved government because resources are now accessible."

Consistently, the researcher also noted that provision of ECDE teaching and learning materials has been the most successful role in resource provision by the County Government of Vihiga. The researcher noted, for instance, that $56.7 \%$ of the respondents agree that there is adequacy and availability of both teaching and learning materials. These findings are consistent with the results from a similar study conducted in Rachuonyo Sub-County which concluded that provision of adequate teaching and learning materials is the cornerstone for the smooth transition 
of preschoolers to primary level of education (Onyango, 2014). It is a given that teaching and learning materials are necessary, especially for the acquisition of higher literacy levels by preschoolers before their transition to primary school, Baker and Brown (2004).

Table 1 also indicates that there is a considerable concern regarding the role played by the County government of Vihiga regarding the provision of human resources. According to Table 1, 36.7\% of respondents confirmed that the human resource is available and adequate, or available but not adequate. Hyde and Kabiru (2006) reported that the best ECDE learning outcomes can only be realized when there is adequate human resource for the learning setting. In retrospect, the inadequacy of the human resource in Vihiga County could point to the lackluster role the County government plays in the implementation of the ECDE curriculum. One QUASO asserted,

"Inadequacy of the human resource in Vihiga County remains one of the greatest challenges in effective ECDE curriculum implementation. And, this trend can be attributed to the introduction of free primary education by the (Kenya) government, and the devolution of ECDE to the county government. There are just too many pupils with a very small number of teachers to take care of them."

As the foregoing discussion has already revealed, there is more to resources than just the financial component. A playground is one such non-financial resource that cannot be wished away. The role played by play in a learning establishment cannot be overemphasized. It does not only play a crucial role in the physical development of the pupils but also in their mental and psychological development. It is also believed that a lot of skills are covertly acquired during play including, but not limited to, learning how to share, learning to take turns and acquiring the skill of collaboration and team work. The aforesaid skills are what make people to behave in a socially acceptable way especially when in the company of others. Notwithstanding the important role of play in a child's physical and psychosocial development, table 1 reveals that only $53.3 \%$ of the respondents agree that there is adequate space to be used as playing ground for the ECDE pupils. This shows that the county government of Vihiga has a long way to go with regards to providing ample space for ECDE pupils to use as playgrounds. Perhaps, this less than adequate provision of playing ground is an important indicator of the level of commitment by the county government towards better implementation of the ECDE program. Nonetheless, the QUASOs and CSOs should ensure that the materials required for optimal functioning of the ECDE centres are of acceptable quality and standards.

\section{B. EFFECTIVENESS OF THE COUNTY GOVERNMENT'S INVOLVEMENT IN THE ECDE CURRICULUM IMPLEMENTATION}

The county government facilitates a range of supervisory practices which are meant to ensure that ECDE centers adhere to certain policy stipulations during the curriculum implementation process. Table two below shows the responses regarding a range of supervisory categories implemented by the county government of Vihiga.

\section{Statement}

ECDE teacher evaluation Practices

Consulting ECDE stakeholders and teachers

regarding Curriculum implementation

Provision of Guidance Direction on Curriculum

Implementation

Provision of In-service training for ECDE teachers

to improve implementation

\begin{tabular}{lccrcrcrcc} 
VE & & E & & D & & I & \multicolumn{3}{c}{ VI } \\
\hline $\mathrm{F}$ & $\%$ & $\mathrm{~F}$ & $\%$ & $\mathrm{~F}$ & $\%$ & $\mathrm{~F}$ & $\%$ & $\mathrm{~F}$ & $\%$ \\
10 & 30 & 8 & 26.7 & 1 & 3.3 & 5 & 16.7 & 4 & 13.3 \\
13 & 43.3 & 9 & 30 & 2 & 7 & 3 & 10 & 3 & 10 \\
16 & 53.3 & 7 & 23.3 & 0 & 0 & 5 & 16.7 & 3 & 10 \\
20 & & 6 & 20 & 0 & 0 & 3 & 10 & 1 & 3.3 \\
66.7 & & & & & & & & &
\end{tabular}

Key: $\mathbf{V}=$ Very effective, $\mathbf{E}=$ Effective, $\mathbf{D}=$ don't know, $\mathbf{I}=$ Ineffective, $\mathbf{V I}=$ Very Ineffective

Table 2 illustrates that each supervisory activity category has a unique inference of the respondents. The general agreement rates among the respondents regarding the effectiveness of devolved government's participation in a supervisory role show a descending trend. Teacher evaluation practices scores the lowest percentage $(30 \%$ at $\mathrm{n}=10)$, while the provision of in-service training for the ECDE teachers scores the highest percentage $(66.7 \%$ at $\mathrm{n}=20)$. Notably, a sizable percentage of the respondents across all statements said that the county government of Vihiga County very ineffectively conducts the supervisory practices. An interview with the one Curriculum Staff Officer yielded the following statement:

"Teacher evaluation practices is one area which my county government has ineffectively implemented. I have always wished that the County government of Vihiga invests in the evaluation practices to improve the participation of teachers in the curriculum evaluation process."

Harris and Sass (2011) reported that the in-service training services provided in an ECDE training center are more efficient than joining training colleges for in-service training. Indeed, the highest percentage reported by respondents corroborates the findings of the authors. However, Consulting ECDE stakeholders and teachers regarding Curriculum implementation and Provision of Guidance Direction on Curriculum Implementation scored $10 \%$ each showing that respondents disagreed on the effectiveness of the county government. This shows that the county government must improve its engagement of both the stakeholders and the provision of direction on the implementation of the ECDE curriculum. Importantly, the results indicate that Vihiga County government has 
managed to improve certain services which were not better under the national government, but still struggles to implement others. Some studies have suggested that the devolved government should collaborate with the central government for effective implementation of the ECDE curriculum. The findings above corroborates the results of a study by Nyachieo (2015) who reported that the input of the central government cannot be overlooked regarding strategies for engaging teachers and other stakeholders in crucial consultation areas. The study emphasized, with Nairobi County as a case study, that devolved governments would play their consultation roles more effectively by engaging the central government through analysis of both successful and failed areas of ECDE curriculum implementation for the benefit of the preschoolers.

\section{TOWARD COUNTY GOVERNMENT'S SUPERVISORY ROLE}

This section examines the specific engagement of the county government through direct activities of both Curriculum Staff Officers, and Quality Assurance Officers (QUASOs). Here, the study sought to establish the level of responsibility and accountability practices by CSOs and QUASOs as a connection between the devolved government and the ECDE teachers during curriculum implementation. Table 3 below shows the results regarding the average number of visits which the officers make to the ECDE centers on an annual basis. The data represents the average number of trips which the officers made to the sampled ECDE centers in Vihiga County in the last five years.

\begin{tabular}{lll}
\hline \hline Stage of ECDE Curriculum Implementation & Frequency & Percentage (\%) \\
\hline \hline ECDE Policy initiation stage & 5 & 35.7 \\
Curriculum implementation stage & 6 & 42.9 \\
Curriculum compliance stage & 3 & 21.4 \\
Impromptu visit to an ECDE center & 0 & 0 \\
\hline \hline Total & $\mathbf{1 4}$ & $\mathbf{1 0 0}$ \\
\hline \hline
\end{tabular}

Table 3 reveals that the Officers frequent the ECDE centers more often during the ECDE curriculum implementation stage $(42.9 \% \mathrm{n}=6)$, compared to 5 visits $(35.7 \%)$ during the ECDE curriculum policy stage. The results imply that policy initiation stage is an important stage where the devolved government engages the teachers on ECDE centers less than it does during the Implementation stage. While compliance to the ECDE curriculum implementation stage is important, the findings show that both QUASO and CSO officers visits the ECDE centers at an average of 3 times (21.4\%) each year. This number of visits corresponds to the number (3) of official school terms in an academic year in Kenya. One headmaster noted:

"The Officers have usually performed excellently during the compliance phase of ECDE curriculum implementation, but compliance follow-up is underperformed. However, compliance follows largely on the leadership of an ECDE center once the policy directive is disseminated by the County Government."

Impromptu visits by the officers imply unannounced visits to the ECDE centers, not necessarily meant for the investigation of compliance levels. Table 3 indicates that there were no such visits by the officers. At times unannounced visits could improve ECDE curriculum implementation by the ECDE leadership of any given center because the leadership would stay prepared by observing the implementation policy requirements.

\section{IV.SUMMARY OF THE FINDINGS}

The study revealed that Vihiga County Government plays an effective role in the implementation of an ECDE curriculum considering the functions of a devolved government. Nonetheless, there are areas which the devolved government performs excellently while other areas requires a concerted effort to improve. For instance, the study showed that resource availability and adequacy is commendable for some resources while others require more input by the county government. Provision of resources such as the ECDE teaching and learning materials remains the County Government's strength, but when it comes to the provision of adequate human resource, the data shows a lackluster performance. That a significant number of respondents believed that ECDE centers are understaffed is perhaps an important wake up call for Vihiga County government to increase the number of qualified ECDE teachers as part of its effort to effectively implement the curriculum.

Furthermore, the findings of this study subtly underscore the importance of a synergy between the national government and the county government of Vihiga in the process of curriculum implementation. For instance, the study revealed that the county government seldom makes efforts to have follow-up visits to ensure adherence to the curriculum implementation requirements. This is where the national government could come in and provide the much needed supervisory support. The central government should not only provide resources for compliance requirements, but also provide necessary guidance on effective implementation of the ECDE curriculum.

\section{References}

Abdumlingo, H., \& Mwirigimugambi, F. (2014). Challenges of Managing Devolved Funds in the Delivery of Services: A Case Study of Mombasa County. CLEAR International Journal of Research in Commerce \& Management, 5(5). 
Baker, L., \& Brown, A. L. (2004). Meta-cognitive development in Creswell, J. W. (2009). Research design: Qualitative, Quantitative and mixed methods approaches. London: Sage.

Harris, D. N., \& Sass, T. R. (2011). Teacher training, teacher quality and student achievement. Journal of Public Economics, 95(7), 798-812.

Hyde, K. A., \& Kabiru, M. N. (2006). Early childhood development as an important strategy to improve learning outcomes. ADEA.

Kiilu, B. M. (2018). Role of County Government in Implementing Pre-Primary School Education in Machakos County, Kenya (Doctoral Dissertation, School of Education, Kenyatta University).

Lutta, J. W. (2013). Factors influencing implementation of early childhood education in Kenya: A case of Matungu sub-county in Kakamega County (Doctoral dissertation, University of Nairobi).

Nyachieo, J. B. (2015). Cooperation between county and central government in provision of early childhood development education a case study of Nairobi County, Kenya (Doctoral dissertation, University of Nairobi).

Obuchere, Z.M. (2011). Factors Influencing Implementation of Early Childhood Development and Education Curriculum in Emuhaya District, Kenya. Maseno University MEd Thesis: Unpublished Report.

Ochieng, P. A. (2018). Devolution of Early Childhood Development and Education in Kenya: Improvement in the Status of Infrastructural Facilities and Its Influence on Enrolment in Siaya County.

Onyango, W. P. (2014). Effects of Teaching and Learning Resources on preschool learners Transition to class one; A case study of rachuonyo South Sub-county. Journal of education andpractice, 5(34). reading. New York, Longman.

Smoke, P. (2015). Rethinking Decentralization: Assessing Challenges to A Popular Public Sector Reform. Public Administration and Development (35), 97-112.

Wakhungu, C. N. (2019). Competencies of public primary school head teachers in managing the implementation of Early Childhood Development Education Programmes in Bungoma County, Bungoma South Sub-County, Kenya (Masters thesis, Moi University).

Wangila, V. M., Omulando, D., \& Too, P. (2017). Influence of Human Resource Capacity to Implementation of ECDE Policy in Bungoma County, Kenya. 